\title{
Kovid 19 ile İlgili Gelişmeleri Kaçırma Korkusu Ölçeğinin Geliştirilmesi: Geçerlik ve Güvenirlik Çalışması
}

DOI: $10.26466 /$ opus. 876588

$*$

\section{Mustafa Pamuk *}

* Dr.Öğr. Üyesi, Selçuk Üniversitesi Eğitim Fakültesi Eğitim Bilimleri Böl. Konya/Türkiye E-Posta: mustafa.pamuk@selcuk.edu.tr

ORCID: $\underline{\text { 0000-0001-8367-4382 }}$

\section{$\ddot{O} z$}

Bu araştırmanın amacı, günümüzde tüm dünyada en önemli gündem maddelerinden olan Kovid 19'la ilgili gelişmeleri kaçırma korkusu üzerine bir ölçek geliştirmektir. Bu amaç doğrultusunda 397 kişi üzerinden Açımlayıcı Faktör Analizi (AFA), 346 kişi üzerinden ise Doğrulayııı Faktör Analizi (DFA) yapılmıştır. Yapılan AFA sonucunda toplam varyansın \%47,867'sini açıklayan, beş maddeden oluşan, tek boyutlu bir yapı elde edilmiştir. Akabinde yapılan DFA sonucuna göre AFA'da elde edilen yapı doğrulanmıştır. Ayrıca elde edilen ölçeğin cinsiyete ve medeni duruma göre ölçüm değişmezlikleri incelenmiştir.Cinsiyette sadece katı değişmezlik săglanamamışken, medeni durumda tüm değişmezlik türleri sağlanmıştır. Ölçüt geçerliği kapsamında Kovid 19'la ilgili gelişmeleri kaçırma korkusu ile gelişmeleri kaçırma korkusu ve Kovid 19 korkusu arasında orta düzeyde, pozitif yönlü; sosyal medya bağımlı̆̆l, internet bağımlı̆̆ı ile düşük düzeyde pozitif yönlü; psikolojik sağlamlıkla ise düşük düzeyde negatif yönlü bir ilişki bulumuştur. Güvenirliğe ilişkin olarak ise hem AFA hem DFA verisi üzerinden Cronbach Alpha ve Mcdonald's $\omega$ değerlerinin 70 üzerinde olduğu bulunmuştur. Elde edilen sonuçlar kapsamında tartışma yapılmış, sınırlllkklardan ve önerilerden bahsedilmiştir.

Anahtar Kelimeler: Kovid 19'la ilgili gelişmleri kaçırma korkusu, kovid 19, kovid 19 korkusu, gelişmeleri kaçırma korkusu. 


\title{
Development of Fear of Missing Out Related to Covid 19 Scale (FoMOC 19S) :Validity and Reliability Study
}

\begin{abstract}
The purpose of this research is to develop a scale on the fear of missing out on developments related to Covid 19, which is one of the most important agenda items in the world nowadays. For this purpose, Explanatory Factor Analysis (EFA) was performed on data collected from 397 people and Confirmatory Factor Analysis (CFA) was performed on data collected from 346 people. As a result of EFA, five items, one-dimensional structure which explains $47,867 \%$ of the total variance was obtained. Subsequently, according to the DFA result, the structure obtained in EFA was confirmed. In addition, measurement invariances of the scale obtained according to gender and marital status were examined. While only strict invariance could not be achieved in gender, all types of invariance in marital status were provided. Within the scope of the criterion validity, a moderate, positive relationship was found between the fear of missing out related to Covid 19 (FoMOC 19) and the fear of missing out (FoMO) and the fear of Covid 19. FoMOC 19 had low-level significant positive relationship with social media addiction and internet addiction; but there was a significant negative, low relationship with psychological resilience. Regarding reliability, Cronbach's Alpha and Mcdonald's $\omega$ values were found to be above .70 on both EFA and CFA data. Discussions were held within the scope of the results obtained, limitations and recommendations were mentioned.
\end{abstract}

Keywords: Fear of missing out related to Covid 19 (FoMOC 19), fear of Covid 19, Covid 19, FoMO. 


\section{Giriş}

Günümüzde dünya genelinde gündem olan konuların başında Kovid 19'la ilgili gelişmeler yer almaktadır. Dünya sağlık örgütü (WHO) istatistiklerine göre, dünya genelinde ölümlerin sayısı iki milyonu aşmış (8 şubat, 2,302,302) ve teyit edilmiş vaka sayısı da 100 milyonun (8 şubat, 105,394,301) üzerine çıkmıştır (WHO, 2021). Aynı istatistiklerde Türkiye'nin ölüm sayısı 30 bine yaklaşmakta (8 şubat, 26,685) ve teyit edilmiş vaka sayısı da üç milyon sınırına doğru yaklaşmaktadır (6 şubat, 2,524,786). Bu resmi rakamların yanında salgının finansal etkileri, 2. dalga söylentileri, mutasyon haberleri gibi gelişmeler insanları kaygılandırabilmektedir. Bu durum insanların hem tedbir almak hem de yeni gelişmeleri kaçırmamak adına Kovid 19 ile ilgili gündemi yakından takip ediyor olabilirler.

Kovid 19'la ilgili gelişmeleri kaçırmaktan bazı kişiler korkabilir. Bu durumun alanyazında gelişmeleri kaçırma korkusuyla (GKK) ilişkili olduğu söylenebilir. GKK "bireyin kendisinin bulunmadı̆̆ı ortamlarda diğer bireylerin ödüllendirici yaşantılara sahip olmasından dolayı yaşadığı yoğun bir endişe hali" olarak tanımlanmaktadır. Ayrıca aynı çalışmada ifade edildiği üzere GKK diğer bireylerin neler yaptıklarına dair gelişmeleri kaçırmamak adına sürekli bağlantıda kalmayı da içeren bir yapıya sahiptir (Przybylski, Murayama, DeHaan ve Gladwell, 2013). Diğer bir tanım da ise GKK “bir kimsenin sosyal etkileşimle ilgili firsatları, ödüllendirici deneyimleri, karl yatırımları veya diğer doyum sağlayıcı yaşantıları kaçırmayla ilgili yaşadığı yoğun kaygı" olarak tanımlanmaktadır (Alt ve Boniel-Nissim, 2018). GKK son ylllarda öne çlkan ve özellikle problemli internet-sosyal medya kullanımı ile ilişkili bir kavramdır (Metin, Pehlivan ve Tarhan, 2017).

GKK'yla ilgili alanyazın incelendiğinde, GKK'nın sosyal medya bağıml-lığıyla (Blackwell, Leaman, Tramposch, Osborne ve Liss, 2017; Karaaslan Eşer ve Ayaz Alkaya, 2019), akıllı telefon bağımlılığıyla (Hishan, Ramakrishnan ve Qureshi, 2020; Traş ve Öztemel, 2019), nomofobiyle (Gezgin, Hamutoglu, Sezen-Gultekin ve Gemikonakli, 2018; Hoşgör ve Hoşgör, 2019), internet bağımlılı̆̆ıyla (Çınar ve Mutlu, 2018; Tang, Hung, Au-Yeung ve Yuen, 2020) pozitif yönlü ilişkili olduğu bulunmuştur. Bunlara ek olarak GKK'nın ruminasyonla (Dempsey, O'Brien, Tiamiyu ve Elhai, 2019), depresyonla (Kartol ve Peker, 2020; Elhai, Gallinari, Rozgonjuk ve Yang, 2020), kaygiyla (HolTe ve 
Ferraro, 2020; Wolniewicz, Rozgonjuk ve Elhai, 2020), hiperaktivite/dürtüsellikle (Çınar ve Mutlu, 2018; Ercengiz, 2020) ve düşük uyku kalitesiyle (Li, Griffiths, Mei ve Niu, 2020) pozitif yönlü ilişkili olduğu bulunmuştur. Teknolojiyle ilişkili yönü dikkate alındığında, teknolojinin karanlık yüzüyle pozitif yönlü ilişkili, psikolojik faktörlerden de negatif olarak ifade edilen değişkenlerle de pozitif yönlü ilişkili olması, GKK'nın bireyler için problemli bir değişken olduğu şeklinde düşünülebilir.

GKK öz belirleme teorisi bağlamında incelendiğinde, psikolojik ihtiyaç tatminlerindeki durumsal veya kronik eksikliklerden kaynaklanan kendi kendini düzenleme belirsizliği olarak anlaşlabilir (Przybylski vd., 2013). Bazı insanlar ilişkileri konusunda endişeli olduklarında, muhtemelen sosyal olarak dişlanmaktan korkarlar (Blackwell vd., 2017). Bu gibi durumlarda bireyler sosyal medyada görünür olmak için paylaşım yapma, paylaşılanları takip etme veya bunları beğenme veya yorum yapma gibi davranışlarda bulunabilirler. Blackwell vd. (2017) göre kaygılı bağlanmaya sahip kişiler ilişkilerini sürdürmek ve sosyal geri bildirim almak için sosyal medyayı kullanabilirler. Ayrıca düşük ihtiyaç doyumu da bireyleri sosyal medya katılımını arttırmakta bu durum da bireylerin GKK'ya karşı savunmasızlı̆ını arttırabilmektedir (Rehman, Goyal, Tandon, Hira ve Ahuja, 2019).

GKK'nın yapısına ilişkin olarak Przybylski vd. (2013) on maddelik, tek boyutlu, öz bildirime dayalı bir ölçme aracı geliştirmişlerdir. Diğer bir tek boyutlu geliştirilen GKK ölçeği ise tek maddelik GKK kısa form ölçeğidir (Riordan vd., 2020). Abel, Buff ve Burr (2016), yetersizlik, kaygı, sinirlilik ve öz saygı gibi psikolojik bileşenleri içeren on madde ve üç alt boyuttan (sense of self, social interaction, and "social anxiety) oluşan bir ölçme aracı geliştirmişlerdir. Weggmann vd. (2017) Przybylski vd.'nin (2013) ölçeğini temel alarak ve birtakım yeni maddeler ekleyerek GKK'yı durumluluk-sürekli GKK şeklinde ele alan iki boyutlu bir ölçme aracı geliştirmişlerdir. Metin, Pehlivan ve Tarhan (2017) ise 22 maddeden oluşan tek boyutlu bir ölçme aracı geliştirmişlerdir. Diğer yeni bir ölçme aracı ise Sette, Lima, Queluz, Ferrari ve Hauck (2020) geliştirilen Online GKK ölçeğidir. Sette vd. (2020) ait olma ihtiyacı, popüler olma ihtiyacı, kaygı ve bağımlılık şeklinde dört alt boyutu içeren yeni bir GKK ölçeği geliştirmişlerdir. Bu On-FoMO ölçeği, Przybylski vd. (2013) ölçeğindeki maddelerinin bazılarında online sosyal medya kullanımını belirtmemiş olduğundan (Ör. "Başkalarının benden daha tatmin edici yaşantılara sahip olması, beni endişelendirir") yola çıkarak tamamı online araçları 
vurgulayan maddeler yazılarak geliştirilmiştir (Sette vd., 2020). Genel olarak çevresindeki bireylerin ödüllendirici yaşantılarını kaçırma olarak ifade edilen GKK'ya (Przybylski vd., 2013) ilişkin geliştirilen ölçekler dikkate alındığında, bu ölçeklerin farklı boyutlarda yapılara sahip oldukları görülmektedir.

Bireyler sadece çevresindeki bireylerin ödüllendirici yaşantılarından uzak kalmaya ilişkin kaygı ve korku yaşamazlar. Aynı zamanda çevresindeki bireylerin yaşamlarındaki oluşabilecek hastalık, ölüm gibi durumları için de kaygı ve korku yaşayabilirler. Bu gibi durumları takip etmek veya haberdar olmak için özellikle sosyal medya araçlarını kullanabilirler. Bazı çalışmalarda sosyal medyanın yakınlarından veya genel gündemden haberdar olmak için kullanıldıklarını gösteren çalışmalar yer almaktadır (Koçer, 2012; Solmaz, Tekin, Herzem ve Demir, 2013; Şener, 2020). Günümüzde Kovid 19'a bağlı olarak bireyler kendilerinin dışında çevresindeki bireylerin durumları için kaygı duyabilmektedirler. Pandemi sürecinde bireylerin çevresindeki kişilerin durumlarını ve Kovid 19'la ilgili gelişmeleri takip etmek için sosyal medyayı kullanmaktadırlar (Çerçi, Canöz ve Canöz, 2020; Küçüktığlı, 2020). Bu durum bireylerin genel GKK davranışlarını göstermelerine neden olabilmektedir. $\mathrm{Bu}$ bağlamda Kovid 19 ile ilgili gelişmeleri kaçırma korkusu, bireylerin yakın çevresindeki (aile, arkadaş vb) ve/veya dünyadaki Kovid 19 ile ilgili gelişmeleri kaçırmakla ilgili yaşadığı korku olarak ifade edilebilir. Bu doğrultulda bireylerin Kovid 19'la ilgili gelişmeleri kaçırma korkularının belirlenebilmesi için bir ölçme aracına ihtiyaç duyulmaktadır. Bu bağlamda bu araştırmada Kovid 19'a bağlı GKK davranışlarını ölçmek için Kovid 19 ile ilgili gelişmeleri kaçırma korkusu (K19-GKK) adında yeni bir ölçme aracı geliştirilmesi amaçlanmıştır.

\section{Yöntem}

Bu kısımda araştırmanın katılımcıları, geliştirilen ölçeğin soru havuzunun oluşturulmasıyla ilgili süreç, veri toplama araçları ve süreç hakkında bilgiler yer almaktadır.

\section{Katılimcilar}

Araştırma kapsamında uygun örnekleme yöntemiyle iki farklı gruptan veri toplanmıştır. İlk grup katılımcılar 251'i kadın, 146'sı ise erkeklerden olmak üzere toplamda 397 bireyden oluşmaktadır. Bu katılımcıların 110'u 18-28 yaş 
aralığında öğrenci olup kalan 287'si 20-62 yaş aralığındaki diğer yetişkinlerden oluşmaktadır (Ort=29.5, Ss=9.4, 18-62). Katılımcıların 184'ü evli, 213'ü ise bekardır. Katılımcıların Kovid 19'a ilişkin durumları incelendiğinde, 47'sinin Kovid 19 hastalı̆̆ını geçirdiği, 235'inin hastalık geçirmediği, 51'inin yakınlarının hastalık geçirdiği, 59'unun kendilerinin hastalığ geçirmediği ama yakınlarının hastalık geçirdiği ve 5 kişinin ise hem kendilerinin hem de yakınlarının hastalığı geçirdiği belirlenmiştir. Katılımcılarının herbirinin en az bir sosyal medya hesabı olduğu belirlenmiştir.

Araştırmanın ikinci grup katılımcılarını, 188'i erkek, 158'i kadın olmak üzere toplamda 346 kişi oluşturmaktadır. Bu katılımcıların 66'sı 18-41 yaş aralığında öğrenci olup kalan 280'i ise 22-57 yaş aralığındaki diğer yetişkinlerden oluşmaktadır (Ort=31.19, Ss=8.11, 18-57). Katılımcıların 186'sı evli, 160'1 ise bekardır. Katılımcıların Kovid 19'a ilişkin durumları incelendiğinde, 51'inin Kovid 19 hastalı̆̆ını geçirmiş, 206'sının hastalık geçirmemiş ve 89'unun ise yakınlarının hastalık geçirmiş olduğu belirlenmiştir. Katılımcılarının herbirinin en az bir sosyal medya hesabı olduğu belirlenmiştir.

\section{Ölçme Araçlan}

Soru Havuzu Oluşturma: K19-GKK ölçeğini geliştirmeden önce, GKK ilgili alanyazındaki tanımlar, geliştirilmiş ölçek çalışmaları (Abel vd., 2016; Metin vd., 2017; Przybylski vd., 2013; Riordan vd., 2020; Sette vd., 2020; Weggmann, vd., 2017) ve diğer ilişkili çalışmalar dikkatlice incelenmiştir. Aynı zamanda Kovid 19'la ilgili yapılan çalışmalar da özellikle gözden geçirilmiştir. Hem GKK çalışmaları hem de Kovid 19 çalışmaları dikkate alınarak madde yazımına başlanmıştır. Ardından 23 maddelik beşli likert tipinde (1= Hiç Uygun Değil - 5=Tamamen Uygun) bir taslak ölçek formu hazırlanmıştır. Hazırlanan taslak form için uzman görüşü olarak 4 rehberlik ve psikolojik danışmanlık (RPD), 1 eğitim teknolojileri ve 1 Türkçe dil uzmanına başvurulmuştur. Ayrıca biri İlköğretim Matematik Öğretmenliği alanında, diğer ikisi RPD alanında üç doktora mezunu ve bir RPD lisans mezunu olan kişilerden ölçeğin anlaşırlılığı üzerine geri bildirim alınmıştır. Gelen geri bildirimler çerçevesinde ölçek formu üzerinde birtakım düzeltmeler yapılmıştır. 23 maddeden 9'u uzman görüşüyle çıkarılmıştır. Analizlere geriye kalan 14 madde ile devam edilmiştir. 
Eksik Kalma Korkusu Ölçeği: Ölçek Przybylski vd. (2013) tarafından geliştirilmiş olup Türkçe'ye Can ve Satıcı (2019) tarafından uyarlanmıştır. Ölçek 10 maddeden oluşan, tek boyutlu, beşli likert tipinde ( $1=$ Hiç beni yansıtmıyor ile $5=$ Tam beni yansıtıyor) ölçüm veren bir ölçme aracıdır (Örnek madde: Arkadaşlarımın neyle meşgul olduklarım bilmemek, beni kaygılandırır). Ölçekten alınabilecek en düşük puan 10 iken en yüksek 50'dir. Puanlar arttıkça gelişmeleri kaçırma korkusu artmaktadır. Can ve Satıcı (2019) güvenirlikle ilgili yaptıkları çalışmada Cronbach Alpha iç tutarlık katsayısını toplam örneklem üzerinden .78 bulmuşlardır. Bu çalışmada ise Cronbach Alpha iç tutarlık katsayısının .81 olduğu bulunmuştur.

Kovid-19 Korkusu Ölçeği: Araştırmada, katılımclların Kovid 19`a ilişkin korku seviyelerini belirlemek amacıyla Ahorsu vd. (2020) tarafından geliştirilen ve Türk toplumu için Satici, Gocet-Tekin, Deniz ve Satici (2020) tarafından uyarlanan Kovid 19 korkusu ölçeği kullanılmıştır. Ölçek tek boyutlu olup 7 maddeden oluşmaktadır (Örnek madde: Koronavirüsten çok korkuyorum). Ölçek maddeleri puanlamaları 1 (kesinlikle katılmıyorum) ile 5 (kesinlikle katılıyorum) arasında değişmektedir. En yüksek ölçek puanı 35 en düşük ise ise 7’dir. Yüksek puan Kovid 19'a yönelik korkunun fazlalığına işaret ederken düşük puan azlığına işaret etmektedir. Ölçeğin Türkçe formu için Cronbach Alpha iç tutarlık katsayısı .84 tür. Bu çalışmada ise Cronbach Alpha iç tutarlık katsayısının .87 olduğu bulunmuştur.

Bergen Sosyal Medya Bağımlılı̆̆ı Ölçeği: Andreassen, Torsheim, Brunborg ve Pallesen'in (2012) geliştirdiği Bergen Sosyal Medya Bağımlılığı Ölçeği altı maddeden oluşmaktadır (Örnek madde: Sosyal medyayı giderek daha fazla kullanma arzusu hissettiniz mi?). Ölçek Türkçe'ye Demirci (2019) tarafından uyarlanmıştır. Ölçekteki maddeler zihinsel uğraş, duygudurum değişikliği, tolerans, yoksunluk, çatışma ve başarısız bırakma girişimi olmak üzere altı temel bağımlılık ölçütünü karşılamaktadır. Ölçek (1) çok nadir ile (5) çok sık arasında değişen beşli Likert tipi derecelendirmeye göre yanıtlanmaktadır. Ölçeğin toplam puanı 6-30 arasında değişmektedir. Özgün ölçeğin iç tutarlılığ .88 olarak bulunmuştur. Bu çalışmada ise Cronbach Alpha iç tutarlık katsay1sinın .86 olduğu bulunmuştur. 
Young İnternet Bağımlılı̆̆ı Ölçeği-Kısa Formu: Ölçek, Young (1998) tarafından geliştirilmiş olup Pawlikowski, Altstötter-Gleich ve Brand (2013) tarafından kısa forma dönüştürülmüştür. Türkçe'ye üniversite öğrencileri ve ergenler için Kutlu, Savcı, Demir ve Aysan (2016) tarafından uyarlanmıştır. Ölçeğin özgün formu internet bağımlılığı düzeyini ortaya koymak amaciyla geliştirilmiştir. Ölçek, 12 maddeden oluşmaktadır ve beşli derecelendirmede (1= Hiçbir zaman, $5=$ Her zaman) şeklinde yapılandırılmıştır (Örnek madde: Hangi sıklıkta planladığınızdan daha fazla internette kalırsınız?). Ölçeğin toplam puanı 12-60 arasında değişmektedir. Ölçeğin iç tutarlık güvenilirlik katsayısı .85 olarak raporlanmıştır. Bu çalışmada ise Cronbach Alpha iç tutarlık katsayısının .90 olduğu bulunmuştur.

Kısa Psikolojik Sağlamlık Ölçeği (KPSÖ): KPSÖSmith vd. (2008) tarafından geliştirilmiş olup Doğan (2015) tarafından Türkçe'ye uyarlamıştır. KPSÖ 6 maddeden oluşmakta olup, $1=$ Hiç uygun değil ile $5=$ Tamamen Uygun şeklinde 5'li Likert tipinde ölçüm veren bir ölçme aracıdır. (Örnek madde: Zor zamanları çok az sıkıntıyla atlatırım). KPSÖ'de 2., 4. ve 6. maddeler ters maddelerdir. Ölçeğin toplam puanı 6-30 arasında değişmektedir. KPSÖ’den yüksek puan almak psikolojik sağlamlığın yüksek olduğunu belirtmektedir. Ölçeğin Cronbach alpha iç tutarlık katsayısı .83 olduğu bulunmuştur. Bu çalışmada ise Cronbach Alpha iç tutarlık katsayısının .82 olduğu bulunmuştur.

\section{Süreç}

Araştırmada öncelikle Selçuk Üniversitesi Sosyal ve Beşeri Bilimler Bilimsel Araştırma ve Yayın Etiği Kurulu'ndan etik kurul raporu alınmıştır (Sayı: E.100887). Araştırmanın verileri çevrim içi olarak Google Form aracilığıyla toplanmıştır. Araştırmanın ilk kısmında katılımcılara araştırmanın amacını belirten bir açıklamaya yer verilmiş, hemen altında da "yukarıdaki bilgileri okudum ve çalışmaya katılmayı kabul ediyorum." şeklinde gönüllü katılımlarını beyan eden bir işaretleme kısmı yer almıştır. Araştırmadan elde edilen veriler öncelikle SPSS'e aktarılmıştır. Bundan sonra Açımlayıcı Faktör Analizi (AFA) için verilerde normallik için maddelerin basıklık ve çarpıklık katsayıları incelenmiştir. Basıklık ve çarpıklığın +/- 2 değerlerinin normal dağılım için kabul edilebilir değerler olduğu kabul edilmektedir (George ve Mallery, 2010). Bazı kaynaklarda normal dağılım için basıklığın +/- 3 olabileceği belirtilmiştir 
(Karagöz, 2019). Curran, West ve Finch (1996) ise çarpıklık değerinin 2 ve basıklığın 7'ye yaklaşmasının problemli olması açısından şüpheli olduğunu, dikkat edilmesi gerektiğini belirtmişlerdir. Analiz sonucunda elde edilen basıklık (0.11-3.13) ve çarpıklık (0.82-1.97) değerlerinin belirtilen kabul edilebilir sınırlar içinde oldukları görülmektedir. Diğer aşamada ortaya çıkan yapıyı doğrulamak için yeni toplanan ikinci bir katılımcı grup üzerinden Doğrulayıcı Faktör Analizi (DFA) yapılmıştır. DFA'da uyum indeksleri olarak $\chi 2 / d f$, Comparative Fit Index (CFI), Goodness of Fit Index (GFI), Root Mean Square Error of Approximation (RMSEA), Standardized Root Mean Square Residual (SRMR) değerleri incelenmiştir. Alanyazında $\chi 2$ /df için kaynaklarda 0-5 arası değerler dikkate alınmaktadır (Aksu, Eser ve Güzeller, 2017; Karagöz, 2019; Özdamar, 2016 ). CFI ve GFI için .>90-<.95 kabul edilebilir, $\geq .95-1$ arası ise iyi uyum kabul edilmektedir (Aksu vd., 2017; Hu ve Bentler, 1999; Özdamar, 2016). RMSEA ve SRMR için .05-.08 arası kabul edilebilir, .05 aşağısı ise iyi uyumu göstermektedir (Brown ve Cudeck, 1993; Hooper, Coughlan ve Mullen, 2008; Hu ve Bentler, 1999; Karagöz, 2019). Ölçeğin güvenirliği için Cronbanch Alpha ile Mcdonald's Omegası hesaplanmıştır. Bu değerlerin .70 üzerinde olması gerektiği belirtilmektedir (Büyüköztürk, 2010; Meng vd., 2020). Ayrıca birleşim geçerliliği için önemli ipucu verdikleri kabul edilen Composite Reliability (CR) ve Average Variance Extracted (AVE) değerleri hesaplanmıştır (Gürbüz, 2019). CR'nin .70'in üstünde, AVE'nin ise .50 üstünde olması beklenmektedir (Hair, Black, Babin ve Anderson, 2014). Son olarak ölçeğin cinsiyete ve medeni duruma göre ölçüm değişmezliği incelenmiştir. Ölçüm değişmezliğinde ise $\chi 2 / \mathrm{df}, \mathrm{CFI}, \mathrm{RMSEA}, \mathrm{SRMR}$ değerleri verilmiş olup ölçüm değişmezliğinin bir üst aşamasına geçmede ise $\Delta$ CFI ve $\Delta \chi 2$ ( $\Delta$ df) değerleri dikkate alınmıştır. $\Delta$ CFI için kritik değer $\Delta$ CFI $\leq .01$ olarak dikkate alınmiştır (Chen, 2007; Cheung ve Rensvold, 2002). Verilerin analizinde SPSS 22, AMOS ve JASP 0.13.1 programları kullanılmıştır.

\section{Bulgular}

Bu kısımda K19-GKK ölçeği'ne ilişkin öncelikle geçerlik analizleri ardından güvenirlik analizleri ve son olarak cinsiyete ve medeni duruma göre ölçüm değişmezliği sonuçları yer almaktadır. 


\section{AFA Bulgularn}

K19-GKK ölçeğinin yapı geçerliliği için öncelikle 14 madde üzerinden AFA yapılmıştır. Verilerin faktör analizi yapmaya uygun olup olmadığını belirlemek amaciyla örneklem uygunluğu (sampling adequacy) ve Barlett Sphericity testleri yapılmıştır. Elde edilen verilerin AFA için uygunluğu için KaiserMeyer-Olkin (KMO) 0.50'den yüksek ve Barlett Küresellik Testi'nin sonucunun anlamlı olması beklenir (Büyüköztürk, 2010; Özdamar, 2016). Elde edilen sonuca göre, KMO'nun .859 olduğu ve Barlett Küresellik Testi'nin de istatistiksel olarak anlamlı olduğu ( $\chi 2=1706,278, \mathrm{Sd}=91, \mathrm{p}=.000)$ bulunmuştur. $\mathrm{Bu}$ sonuçlara göre verilerin AFA'ya uygun olduğu söylenebilir. AFA'da 14 madde üzerinde öncelikle herhangi bir boyut kısıtlaması olmadan analiz yapılmıştır. Elde edilen özdeğerler dikkate alındığında özdeğeri 1'in üzerinde üç boyut olmasından dolayı döndürme işlemi yapılmıştır. Döndürme işleminde temel eksenler yöntemi (TEY) ve promax döndürme tekniği kullanılmıştır. Alanyazında AFA yapılırken faktör yük değerleri için . 45 ve daha yüksek değerlerin seçilmesi iyi bir ölçüdür (Büyüköztürk, 2010). Bu çalışmada ise faktör yükleri için .55 değeri tercih edilmiştir. Tablo 1'de de görüldüğü üzere, ölçüt olarak .55 faktör yük değerinin dikkate alındığı TEY ve promax döndürme sonuçlarına göre dokuz madde $(4,5,6,9,10,11,12,13,14) .55$ faktör yük değerinin altında olduğu için analizden çıkarılmışlardır. Her bir madde çıarilırken analiz tekrarlanmıştır. Geriye kalan beş maddeden toplam varyansın \%47,867'sini açıklayan, tek boyutlu bir yapı elde edilmiştir. Tek faktörlü desenlerde açıklanan varyansın \% 30 ve daha fazla olmasının yeterli oldugu belirtilmektedir (Büyuiköztürk, 2010). bu bağlamda elde edilen \%47,867'i varyans değerinin yeterli olduğu söylenebilir.

Tablo 1'de görüldüğü üzere, faktör yük değerlerinin .60-.79 arasında değiştiği görülmektedir. Madde-toplam korelasyonunun negatif olmaması ve .30 'dan daha yüksek olması maddelerin benzer davranışları örneklemesi (Büyüköztürk, 2010) ve ölçeğin toplanabilirlik özelliğinin bozulmaması (Kalaycı, 2005) için önemlidir. Bu çalışmada da düzeltilmiş madde-toplam korelasyon değerlerine bakıldığında madde toplam korelasyon değerlerinin .54 -.70 arasinda değer aldığı görülmektedir. Bu sonuçlar da maddelerin benzer davranışları ölçtüğüne ve ölçeğin maddelerinin toplanabilirlik özelliğinin bozulmadığına işaret etmektedir. 
Tablo 1 . AFA, DFA faktör yükleri, düzeltilmiş maddde-toplam korelasyon değerleri, ortalama / standart sapma değerleri

\begin{tabular}{|c|c|c|c|c|c|}
\hline $\begin{array}{l}\text { İlk } \\
\text { ölçek madde } \\
\text { sırası }\end{array}$ & $\begin{array}{l}\text { AFA'dan } \\
\text { sonraki madde } \\
\text { surası }\end{array}$ & $\begin{array}{l}\text { AFA } \\
\text { Faktör Yükleri } \\
(\mathrm{N}=397)\end{array}$ & $\begin{array}{l}\text { Düzeltilmiş maddde-toplam } \\
\text { korelasyon değerleri }\end{array}$ & $\begin{array}{l}\text { DFA } \\
\text { Faktör } \\
(\mathrm{N}=346)\end{array}$ & $\begin{array}{r}\text { Standardize } \\
\text { Yükleri }\end{array}$ \\
\hline 3 & 1 & .79 & .70 & .92 & \\
\hline 1 & 2 & .78 & .70 & .78 & \\
\hline 8 & 3 & .64 & .54 & .65 & \\
\hline 7 & 4 & .62 & .55 & .54 & \\
\hline 2 & 5 & .60 & .54 & .61 & \\
\hline
\end{tabular}

Özdeğer=2.893

Açılanan Toplam Varyans $=\% 47,867$

\section{DFA Bulgularn}

Bu kısımda AFA ile elde edilen yapının farklı bir örneklem üzerinde doğrulanması amacıyla yapılan doğrulayıcı faktör analizine ilişkin bulgular yer almaktadir.

\section{Tablo 2. DFA uyum indeks değerleri}

\begin{tabular}{lllllllllll}
\hline $\mathrm{N}$ & $\chi 2$ & $\mathrm{Df}$ & $\mathrm{p}$ & $\chi 2 / \mathrm{df}$ & $\mathrm{CFI}$ & $\mathrm{TLI}$ & $\mathrm{GFI}$ & AGFI & RMSEA & SRMR \\
\hline Illk model & 99.815 & 5 & .000 & 19.963 & .878 & .756 & .899 & .697 & .234 & .0680 \\
\hline $\begin{array}{l}\text { Modifiye } \\
\text { model }\end{array}$ & 6.737 & 4 & .150 & 1.684 & .996 & .991 & .993 & .972 & .045 & .0165 \\
\hline
\end{tabular}

Yapılan AFA analizinden elde edilen tek boyutlu yapıyı doğrulamak için farklı bir örneklem grubundan elde edilen veriler üzerinden DFA yapılmıştır. DFA sonuçlarına ilişkin uyum indeks değerleri Tablo 2' de yer almaktadır. Illk analiz sonuçlarında yeterli uyum indeksleri $(\chi 2 / \mathrm{df}=19.963, \mathrm{CFI}=.878$, TLI=.756, GFI=.899, AGFI=.697, RMSEA=.234 ve SRMR=.0680) elde edilemediği için modifikasyon yapılmıştır. Modifikasyon olarak M7-M8 maddelerinin hata varyansları arasına kovaryans eklenmiş ve Tablo 2' deki değerler bulunmuştur. Buna göre $\chi 2 / \mathrm{df}=1.684, \mathrm{CFI}=.996, \mathrm{TLI}=.991, \mathrm{GFI}=.993$, AGFI=.972, RMSEA $=.045$ ve $S R M R=.0165$ olarak bulunmuştur. Modifikasyon sonrası değerlerin iyi uyum seviyesinde oldukları belirlenmiştir (Aksu, vd. 2017; Brown ve Cudeck, 1993; Hooper vd. 2008; Hu ve Bentler, 1999; Karagöz, 2019; Özdamar, 2016). Ayrıca Tablo 1 incelendiğinde, elde edilen DFA sonuçlarına göre, standardize faktör yük değerlerinin .54 - .92 arasında değer aldıkları görülmektedir.

Tablo 3'te görüldüğüü üzere, K19-GKK ile diğer değişkenler arasında yap1lan korelasyon analizine göre, K19-GKK ile sirasiyla FoMO ile Kovid 19 kor- 
kusuyla orta düzeyde pozitif yönlü bir ilişki (r346=.51; r397=.40) olduğu bulunmuştur.

Tablo 3. K19-GKK ile diğer ölçekler arasındaki korelasyon değerleri

\begin{tabular}{llllll}
\hline & $\begin{array}{l}\text { FoMO } \\
(\mathrm{N}=346)\end{array}$ & $\begin{array}{l}\text { Covid } \\
\text { Korkusu } \\
(\mathrm{N}=397)\end{array}$ & $\begin{array}{l}\text { İnternet } \\
\text { Bağımlı̆ı̆̆ } \\
(\mathrm{N}=397)\end{array}$ & $\begin{array}{l}\text { Sosyal Medya } \\
\text { Bağımlılığı } \\
(\mathrm{N}=397)\end{array}$ & $\begin{array}{l}\text { Psikolojik } \\
\text { Sağlamlık } \\
(\mathrm{N}=397)\end{array}$ \\
\hline K19-GKK & $.51^{*}$ & $.40^{*}$ & $.16^{*}$ & $.15^{*}$ & $-.23^{*}$ \\
\hline
\end{tabular}

${ }^{*} \mathrm{p}<.01$

Ayrıca K19-GKK ile internet bağımlllı̆̆ ve sosyal medya bağımlılığı arasinda düşük düzeyde pozitif yönlü bir ilişki (r397=.16; r397=.15) varken psikolojik sağlamlıkla arasında düşük düzeyde negatif yönlü bir ilişki (r397=23) olduğu bulunmuştur.

Tablo 4. K19-GKK için Cronbach Alpha, McDonald's Omega, AVE ve CR değerleri

\begin{tabular}{lllllllll}
\hline & $\begin{array}{l}\text { Cronbach } \\
\text { Alpha } \\
(\mathrm{N}=397)\end{array}$ & $\begin{array}{l}\text { Cronbach } \\
\text { Alpha } \\
(\mathrm{N}=346)\end{array}$ & $\begin{array}{l}\text { McDonald's } \\
(\mathrm{N}=397)\end{array}$ & $\begin{array}{l}\text { McDonald's } \\
(\mathrm{N}=346)\end{array}$ & $\omega$ & AVE & CR \\
\hline K19-GKK & .79 & .84 & .82 & .84 & .51 & .83 \\
\hline
\end{tabular}

Tablo 4'te görüldüğü üzere, güvenirliğe ilişkin olarak yapılan Cronbach Alpha iç tutarlık katsayıları AFA verisi üzerinden .79; ikinci yeni örneklem verisi üzerinden ise .84 olarak bulunmuştur. Diğer bir güvenirlik testi olan Mcdonald's $\omega$ 's1 EFA verisi üzerinden .82; ikinci yeni örneklem olan DFA verisi üzerinden ise .84 olduğu bulunmuştur. Ayrıca CR değeri .83 olarak hesaplanmıştır. Son olarak da AVE değerinin .51 olduğu bulunmuştur.

Tablo 5. Cinsiyete Göre Ölçüm Değişmezliği İçin Uyum Değerleri

\begin{tabular}{|c|c|c|c|c|c|c|c|}
\hline Modeller & $\begin{array}{l}\text { CMIN } \\
\text { (df) }\end{array}$ & $\begin{array}{l}\text { CMIN/ } \\
\text { (df) }\end{array}$ & SRMR & RMSEA & CFI & $\Delta \chi^{2}(\Delta d f)$ & $\Delta \mathrm{CFI}$ \\
\hline $\begin{array}{l}\text { 1. Yapısal / Biçim } \\
\text { değişmezliği }\end{array}$ & $15.607^{*}(8)$ & 1.951 & .0248 & .053 & .990 & & \\
\hline 2. Metrik değişmezlik & $22.308^{*}(13)$ & 1.716 & .0244 & .046 & .988 & $\begin{array}{l}6.700 \text { (5) } \\
\text { (Model1- } \\
\text { Model 2) }\end{array}$ & $\begin{array}{l}.002 \\
\text { (Model1- } \\
\text { Model 2) }\end{array}$ \\
\hline 3. Ölçek değişmezliği & $25.143^{*}(18)$ & 1.397 & .0242 & .034 & .991 & $\begin{array}{l}2.835(5) \\
\text { Model2- } \\
\text { Model 3) }\end{array}$ & $\begin{array}{l}-.003 \\
\text { (Model2- } \\
\text { Model 3) }\end{array}$ \\
\hline 4. Katı değişmezlik & $45.650^{*}(24)$ & 1.902 & .0349 & .051 & .973 & $\begin{array}{l}20.507^{*}(6) \\
(\text { Model3- } \\
\text { Model 4) }\end{array}$ & $\begin{array}{l}.018 \\
\text { (Model3- } \\
\text { Model 4) }\end{array}$ \\
\hline
\end{tabular}

${ }^{*} \mathrm{p}<.05, \mathrm{~N}=346 ; \mathrm{N}_{\text {kadin }}=158, \mathrm{~N}_{\text {erkek }}=188$ 
K19-GKK ölçeğinin cinsiyete göre ölçüm değişmezliği incelenmiştir. Ölçüm değişmezliğinde bir üst aşamaya geçmede $\Delta \chi^{2}(\Delta \mathrm{df})$ ve $\Delta$ CFI değerleri dikkate alınmıştır. $\Delta$ CFI için kritik değer $\Delta$ CFI $\leq .01$ olarak dikkate alınmıştır (Chen, 2007; Cheung ve Rensvold, 2002). Yapılan çok gruplu DFA sonucunda elde edilen uyum değerlerinin $(\chi 2 / \mathrm{df}=1.951, \mathrm{CFI}=.99$, $\mathrm{RMSEA}=.053$ ve SRMR=.0248) iyi uyum içinde olması yapısal denkliğin sağlandığını göstermektedir. Biçimsel değişmezliğin sağlanmış olması, K19-GKK ölçeği ile ölçülen yapının gruplar arasında aynı olduğuna ve erkek ile kadın katılımcıların K19-GKK ölçeği maddelerine cevap vermede benzer kavramsal bakış aç1larını kullandıklarına işaret etmektedir (Başusta ve Gelbal, 2015). İkinci aşamada test edilen metrik değişmezlik için elde edilen uyum değerlerinin $(\chi 2 / \mathrm{df}=1.716, \mathrm{CFI}=.988, \mathrm{RMSEA}=.046$ ve SRMR=.0244) iyi uyum değerlerine sahip olması, yapısal model ile metrik denklik karşılaştıııldığında $\chi 2$ değerinin 6.700 olması ve bu farkın anlamsız olması ( $p=.244)$ ve biçimsel değişmezliğin CFI'si ile metrik değişmezliğin CFI'sinin farkının $\triangle \mathrm{CFI}=.002$ olması metrik değişmezliğin sağlandığını göstermektedir (Ölçüt: $\Delta \mathrm{CFI} \leq .01$ ). Metrik değişmezliğin sağlanmış olması, K19-GKK ölçeği maddelerine benzer şekilde cevapladıkları ve ilgili faktör yüklerinin gruplar arasında eşitliğine kanıt olarak ele alınabilir (Gürbüz, 2019). Üçüncü aşamada ise ölçek değişmezliği test edilmiş ve uyum değerlerinin iyi uyum değerlerine sahip olması $(\chi 2 / \mathrm{df}$ =1.397, CFI=.991, RMSEA=.034 ve SRMR=.0242), metrik değişmezlik ile ölçek değişmezliği karşılaştırıldığında $\chi 2$ değerinin 2.835 olması ve bu farkın anlamsız olması ( $(\mathrm{p}=.725)$ ve metrik değişmezliğin CFI'si ile ölçek değişmezliğinin CFI'sinin farkının $\Delta \mathrm{CFI}=-.003$ olması ölçek değişmezliğinin sağlandığını göstermektedir (Ölçüt: $\Delta \mathrm{CFI} \leq .01$ ). Ölçek değişmezliğinin sağlanmış olması, maddeler bazında kadın ve erkek gruplar için herhangi bir yanlılığın olmadığ 1 şeklinde ifade edilebilir (Başusta ve Gelbal, 2015). Son olarak ise katı değişmezlik test edilmiştir. Uyum değerleri kabul edilebilir düzeyde $(\chi 2 / \mathrm{df}$ $=1.902, \mathrm{CFI}=.973, \mathrm{RMSEA}=.051$ ve $\mathrm{SRMR}=.0349$ ) olmasina rağmen $\Delta \mathrm{CFI}=.018$ ve ölçek değişmezliği ile katı değişmezlik karşılaştırıldığında $\chi 2$ değerinin 20.507 olması ve bu farkın anlamlı olması $(\mathrm{p}=.002)$ katı değişmezliğinin sağlanmadığını şeklinde ifade edilebilir (Ölçüt: $\Delta \mathrm{CFI} \leq .01$ ). Katı değişmezliğe ilişkin elde edilen sonuca göre maddelerin hata varyanslarının eşit olmadığ söylenebilir (Gürbüz, 2019). 
Tablo 6. Medeni duruma Göre Ölçüm Değişmezliği İçin Uyum Değerleri

\begin{tabular}{|c|c|c|c|c|c|c|c|}
\hline Modeller & $\mathrm{CMIN}(\mathrm{df})$ & $\begin{array}{l}\text { CMIN/ } \\
\text { (df) }\end{array}$ & SRMR & RMSEA & CFI & $\Delta \chi^{2}(\Delta \mathrm{df})$ & $\Delta \mathrm{CFI}$ \\
\hline Yapısal / Biçim değişmezliği & $12.289(8)$ & 1.536 & .0228 & .039 & .995 & & \\
\hline Metrik değişmezlik & $17.227(13)$ & 1.325 & .0311 & .031 & .995 & $\begin{array}{l}4.938 \text { (5) } \\
\text { (Model1- } \\
\text { Model 2) }\end{array}$ & $\begin{array}{l}.000 \\
\text { (Model1- } \\
\text { Model 2) }\end{array}$ \\
\hline Ölçek değişmezliği & $19.236(18)$ & 1.069 & .0311 & .014 & .998 & $\begin{array}{l}2.010(5) \\
\text { Model2- } \\
\text { Model 3) }\end{array}$ & $\begin{array}{l}-.003 \\
\text { (Model2- } \\
\text { Model 3) }\end{array}$ \\
\hline Katı değişmezlik & $30.904(24)$ & 1.288 & .0381 & .029 & .993 & $\begin{array}{l}11.667 \text { (6) } \\
\text { (Model3- } \\
\text { Model 4) }\end{array}$ & $\begin{array}{l}.005 \\
\text { (Model3- } \\
\text { Model 4) }\end{array}$ \\
\hline
\end{tabular}

${ }^{*} \mathrm{p}<.05, \mathrm{~N}=346 ; \mathrm{Nevli}=186, \mathrm{~N}_{\text {bekar }}=160$

K19-GKK ölçeğinin medeni duruma göre ölçüm değişmezliği incelenmiştir. Ölçüm değişmezliğinde bir üst aşamaya geçmede $\Delta \chi^{2}(\Delta \mathrm{df})$ ve $\Delta$ CFIdeğerleri dikkate alınmıştır. $\Delta \mathrm{CFI}$ için kritik değer $\Delta \mathrm{CFI} \leq .01$ olarak dikkate alınmıştır (Chen, 2007; Cheung ve Rensvold, 2002). Yapılan çok gruplu DFA sonucunda elde edilen uyum değerlerinin $(\chi 2 / \mathrm{df}=1.536$, CFI=.995, RMSEA=.039 ve SRMR=.0228) iyi uyum içinde olması yapısal denkliğin sağlandığını göstermektedir. Biçimsel değişmezliğin sağlanmış olması, K19GKK ölçeği ile ölçülen yapının gruplar arasında aynı olduğuna ve evli ile bekar katılımcıların K19-GKK ölçeği maddelerine cevap vermede benzer kavramsal bakış açılarını kullandıklarına işaret etmektedir (Başusta ve Gelbal, 2015). İkinci aşamada test edilen metrik değişmezlik için elde edilen uyum değerlerinin $(\chi 2 / \mathrm{df}=1.325, \mathrm{CFI}=.995$, $\mathrm{RMSEA}=.031$ ve $\mathrm{SRMR}=.0311)$ iyi uyum değerlerine sahip olması, yapısal model ile metrik denklik karşılaştırıldığında $\chi 2$ değerinin 4.938 olması ve bu farkın anlamsız olması $(\mathrm{p}=.424)$ ve biçimsel değişmezliğin CFI'si ile metrik değişmezliğin $\mathrm{CFI}^{\prime}$ sinin farkının $\Delta \mathrm{CFI}=.000$ olması metrik değişmezliğin sağlandığını göstermektedir (Ölçüt: $\Delta \mathrm{CFI} \leq .01)$. Metrik değişmezliğin sağlanmış olması, K19-GKK ölçeği maddelerine benzer şekilde cevapladıkları ve ilgili faktör yüklerinin gruplar arasında eşitliğine kanıt olarak ele alınabilir (Gürbüz, 2019). Üçüncü aşamada ise ölçek değişmezliği test edilmiş ve uyum değerlerinin iyi uyum değerlerine sahip olmas1 $(\chi 2 / \mathrm{df}=1.069, \mathrm{CFI}=.998$, RMSEA=.014 ve SRMR=.0311), metrik değişmezlik ile ölçek değişmezliği karşılaştırıldığında $\chi 2$ değerinin 2.010 olması ve bu farkın anlamsız olması $(p=.848)$ ve metrik değişmezliğin CFI'si ile

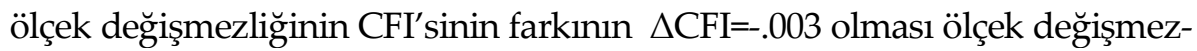
liğinin sağlandığını göstermektedir (Ölçüt: $\Delta \mathrm{CFI} \leq .01$ ). Ölçek değişmezliğinin sağlanmış olması, maddeler bazında evli ve bekar gruplar için herhangi 
bir yanlılığın olmadığı şeklinde ifade edilebilir (Başusta ve Gelbal, 2015). Son olarak ise katı değişmezlik test edilmiştir. Uyum değerleri kabul edilebilir düzeyde ( $\chi 2 / \mathrm{df}=1.288, \mathrm{CFI}=.993$, RMSEA=.029 ve SRMR=.0381) olmas1, ölçek değişmezliği ile katı değişmezlik karşılaştırıldığında $\chi 2$ değerinin 11.667 olması ve bu farkın anlamlı olmaması ( $\mathrm{p}=.07)$ ve $\Delta$ CFI değerinin $\Delta \mathrm{CFI}=.005$ olması katı değişmezliğinin sağlandığını şeklinde ifade edilebilir (Ölçüt: $\Delta \mathrm{CFI} \leq .01$ ). Katı değişmezliğe ilişkin elde edilen sonuca göre maddelerin hata varyanslarının eşit olduğu söylenebilir (Gürbüz, 2019).

\section{Sonuç, Tartışma ve Öneriler}

$\mathrm{Bu}$ araştırmada günümüzde gündem konularının başında gelen konulardan biri olan Kovid 19'la ilgili gelişmeleri kaçırma korkusunu ölçen bir ölçme aracı geliştirilmiştir. Alanyazındaki FoMO'yla ilişkili ölçek ve ilgili alanyazının yanısıra Kovid 19'la ilgili çalışmalar da dikkate alınarak hazırlanan K19GKK için yapılan AFA sonucunda beş maddeden oluşan, tek boyutlu bir yapı elde edilmiştir (Bkz. EK 1). Bu yapıyı daha sonrasında başka bir örneklem üzerinden doğrulamak için yapılan DFA sonucunda yapının doğrulandığ görülmüştür. Doğrudan Kovid 19'la ilgili gelişmeleri kaçırma üzerine geliştirilmiş bir ölçeğe rastlanılmasa da K19-GKK'nın çıkış noktası olan FoMO'yla ilgili geliştirilen ölçekler dikkate alındığında; K19-GKK'nın tek boyutlu yapısı; Metin vd. (2017). Przybylski vd. (2013) ve Riordan vd. (2020) ölçeklerinin tek boyutlu yapılarıyla benzerlik göstermekte iken Abel vd.'nin (2016) üç alt boyutlu, Sette vd.'nin (2020) dört alt boyutlu ve Weggmann. vd.'nin (2017) iki alt boyutlu olan ölçeklerin çok alt boyutlu yapılarıyla farklılık göstermektedir.

Araştırmada K19-GKK için elde edilen güvenirlik katsayıları incelediğinde, hem AFA verisi üzerinden hem de DFA verisi üzerinden hesaplanan Cronbach Alpha ve Mcdonald's omega değerlerinin iyi düzeyde olduğu görülmektedir (Büyüköztürk, 2010; Meng vd., 2020). Ayrıca CR için elde edilen değerin .83 olması, AVE'nin .51 olması ve CR>AVE olması birleşim geçerliliğinin sağlandığı şeklinde söylenebilir (Gürbüz, 2019). Ayrıca yapılan ölçüt geçerliliği çalışmalarında K19-GKK ile FoMO ve Kovid 19 korkusu arasında orta düzeyde pozitif yönlü bir ilişki bulunmuştur. K19-GKK ile internet bağımlılı̆̆ ve sosyal medya bağımlılığı arasında düşük düzeyde pozitif yönlü bir ilişki varken psikolojik sağlamlıkla ise düşük düzeyde negatif yönlü bir 
ilişki olduğu bulunmuştur. Bu sonuçlara bakıldığında K19-GKK'nın fikir çıkış noktası olan FoMO ile r=.51 düzeyinde bir ilişkiye sahip olması ve K19GKK'yı FoMO ölçeğinden farklılaştıran kısmı olan Kovid 19 faktörüyle ilişkili olan Kovid 19 korkusu ölçeğiyle K19-GKK'nın r=.40 düzeyinde bir ilişkiye sahip olması ve düşük düzeyde de olsa sosyal medya bağımlılı̆̆ ve internet bağımlılıyla da pozitif yönlü ilişkili olması, K19-GKK'nın geliştirilme amacına hizmet ettiğine ilişkin kanıtlar olarak ele alınabilir.

Araştırmada K19-GKK'nın cinsiyete göre ölçüm değişmezliği analizlerinden elde edilen sonuca göre, K19-GKK'nın biçimsel, metrik ve ölçek değişmezliklerinin sağlandığı; ancak katı değişmezliğin sağlanmadığı bulunmuştur. Bu sonuçlara göre erkek ile kadın katılımcıların K19-GKK maddelerine cevap verirken bakış açılarının kavramsal bağlamda benzer olduğu, ölçek maddelerini benzer biçimde yanıtladıkları, kadın ve erkek gruplar için maddeler bağlamında yanlılığın olmadığl; ancak hata varyanslarının eşit olmadığ 1 şeklinde yorumlanabilir (Başusta ve Gelbal, 2015; Gürbüz, 2019). Bu sonuca göre araştırmacıların K19-GKK'yı cinsiyete göre incelemelerinde bu durumu göz önünde bulundurmaları faydalı olacaktır. Araştırmada ölçüm değişmezliği için ele alınan diğer bir değişken ise medeni durumları olmuştur. Elde edilen sonuçlara göre ölçüm değişmezliği için Tüm değişmezlik aşamaları sağlandığı için ilerde K19-GKK'yı çalışacak araştırmacılar için K19GKK'yı medeni duruma göre çalışmaları anlamlı olacaktır. K19-GKK'ya ilişkin olarak ileride yapılması planlanan çalışmalarda cinsiyet ve medeni durum dışında farklı değişkenler dikkate alınarak ölçüm değişmezlileri incelenebilir.

Araştırmadan elde edilen sonuçlar genel olarak değerlendirildiğinde, koronavirüs gündemini ve gelişmeleri kaçırma korkusu yapısını dikkate alınarak hazırlanan K19-GKK ölçeğinin beş madde, tek boyutlu yapısıyla geçerli ve güvenilir bir ölçüm veren bir ölçme aracı olduğu söylenebilir. Ölçeğin alanyazında ilk olması, kısa olması, cinsiyete ve medeni durumlara ilişkin ölçüm değişmezliğinin yapılmış olması, 18-62 (AFA grubu) - 18-57 (DFA grubu) geniş yaş aralıklarıyla çalışılmış olması artı yönleri olarak görülürken ergenlerle çalışılmamış olması, cinsiyet ve medeni durumların dışında ölçüm değişmezliğinin çalışılmamış olması gibi durumlarda eksi yönleri olarak görülebilir. Ayrıca ilerleyen çalışmalarda kaygı, stres, iyi oluş, kişilik gibi kavramlarla çalışılabilir. 


\title{
EXTENDED ABSTRACT
}

\section{Development of Fear of Missing Out Related to Covid 19 Scale (FoMOC 19S): Validity and Reliability Study}

\author{
Mustafa Pamuk \\ Selçuk University
}

Developments related to Covid 19 are at the top of the agenda around the world nowadays. According to the statistics of the World Health Organization $(\mathrm{WHO})$, the number of deaths worldwide has exceeded two million (8 February, 2,302,302) and the number of confirmed cases has exceeded 100 million (8 February, 105,394,301). The same statistics the number of deaths in Turkey is approaching 30 thousand (February $8,26.685$ ) and the number of confirmed cases is also closer to three million (6 February, 2,524,786). In addition to these official numbers, developments such as the financial effects of the epidemic, 2nd wave rumors, mutation news may worry people. In this case, people may follow the agenda about Covid 19 closely in order to take precautions and not to miss new developments.

Some people may be afraid of missing out on developments regarding Covid 19. It can be said that this situation is related with the fear of missing out (FoMO) in the literature. FoMO was defined as "a pervasive apprehension that others might be having rewarding experiences from which one is absent" (Przybylski, Murayama, DeHaan and Gladwell, 2013). In another definition, FoMO was defined as "an anxiety, whereby one is compulsively concerned that he/she might miss an opportunity for social interaction, a rewarding experience, profitable investment or other satisfying events" (Alt and Boniel-Nissim, 2018).

Individuals do not only experience anxiety and fear of being deprived of the rewarding lives of the individuals around them, but they may also experience anxiety and fear for situations such as illness and death that may occur in the lives of the individuals around them. They can especially use social media tools to follow up or be informed about such situations. In some studies, there are studies showing that social media are used to be aware of their 
close circle or general world agenda (Koçer, 2012; Solmaz, Tekin, Herzem, and Demir, 2013; Şener, 2020). Nowadays, due to Covid 19, individuals may worry about the conditions of the individuals around them as well as for themselves. During the pandemic process, they use social media to follow the situations of the people around individuals and the developments related to Covid 19 (Çerçi, Canöz and Canöz, 2020; Küçüktı̆̆ll, 2020). This situation may cause individuals to display general FoMO behaviors. In this context, fear of missing out related to Covid19 (FoMOC 19) can be defined as the fear that individuals experience about missing out the developments related to Covid 19 in their close circle (family, friends, etc.) and / or in the world. In this direction, a measurement tool is needed to determine the fears of individuals about missing the developments related to Covid 19. In this context, in this study, it was aimed to develop a new measurement tool called Fear of Missing Out related to Covid 19 Scale (FoMOC 19S).

Within the scope of the research, data were collected from two different groups using the appropriate sampling method. The first group of participants consists of a total of 397 individuals, of which 251 are women and 146 are men. The second group of participants of the study consists of a total of 346 people, 188 of whom are men and 158 of them are women.

Before developing the FoMOC 19S, definitions in the related literature, developed scale studies (Abel et al., 2016; Metin et al., 2017; Przybylski et al., 2013; Riordan et al., 2020; Sette et al., 2020; Weggmann, et al., 2017) and other studies related to general FoMO were carefully examined. At the same time, studies on Covid 19 were especially reviewed. The items were written considering both FoMO studies and Covid 19 studies. Subsequently, a draft scale form with a 23 -item five-point Likert type ( $1=$ Not at all appropriate $-5=$ Completely appropriate) was prepared. For the draft form prepared, 4 guidance and psychological counseling (GPC), 1 educational technologies and 1 Turkish language expert were consulted as expert opinion. In addition, feedbacks were received from three $\mathrm{PhD}$ (an elementary mathematics education and two GPC) and an undergraduate (GPC) on the understandability of the scale. Some corrections were made on the scale form within the framework of the feedback. 9 out of 23 items were removed with expert opinion. The analyzes were continued with the remaining 14 items.

The scale was developed by Przybylski et al. (2013) and adapted to Turkish by Can and Seller (2019). 
Ahorsu et al. (2020) developed the scale. The scale was adapted to Turkish Society by Satici, Gocet-Tekin, Deniz and Satici (2020). Bergen Social Media Addiction Scale: The scale developed by Andreassen, Torsheim, Brunborg and Pallesen (2012) and was adapted to Turkish by Demirci (2019). The scale was developed by Young (1998) and converted into short form by Pawlikowski, Altstötter-Gleich, and Brand (2013). It was adapted into Turkish for university students and adolescents by Kutlu, Savcl, Demir and Aysan (2016). The scale was developed by Smith et al. (2008) and was adapted to Turkish by Doğan (2015).

In the research, the ethics committee report was taken from the Selcuk University Social and Humanities Scientific Research and Publication Ethics Committee (No : E.100887). The research data were collected online via Google Form. In the first part of the study, the purpose of the research was given to the participants and there was a marking part that declares voluntary participation in the form. EFA was performed to determine construct. The kurtosis and skewness coefficients of the items were examined for normality in the data for the Explanatory Factor Analysis (EFA). It was seen that kurtosis (0.11-3.13) and skewness (0.82-1.97) values obtained as a result of the analysis were within acceptable limits (Curran, West and Finch, 1996; George and Mallery, 2010; Karagöz, 2019). Then CFA was performed to confırm structure obtained from the EFA analysis. Cronbach Alpha and Mcdonald's Omega coefficients were calculated for the reliability of the scale. In addition, Composite Reliability (CR) and Average Variance Extracted (AVE) values, which are considered to give important clues for combination validity, were calculated (Gürbüz, 2019). Finally, the measurement invariance of the scale according to gender and marital status was examined. In the measurement invariance, $\chi 2$ / df, CFI, RMSEA, SRMR values were given, and $\triangle \mathrm{CFI}$ and $\Delta \chi 2$ (df) values were taken into account when moving to the next stage of measurement invariance. The critical value for $\Delta \mathrm{CFI}$ is considered as $\Delta \mathrm{CFI} \leq .01$ (Chen, 2007; Cheung and Rensvold, 2002). SPSS 22, AMOS and JASP 0.13.1 programs were used to analyze the data.

For the construct validity of the FoMOC 19 scale, first EFA was performed over 14 items. Sampling adequacy and Barlett Sphericity tests were conducted to determine whether the data were suitable for factor analysis. For the suitability of the obtained data for EFA, Kaiser-Meyer-Olkin (KMO) is expected to be higher than 0.50 and the result of the Barlett Sphericity Test is 
expected to be significant (Büyüköztürk, 2010; Özdamar, 2016). According to the result obtained, $\mathrm{KMO}$ was found to be .859 and Bartlett's Test of Sphericity was found to be statistically significant $(\chi 2=1706,278, S d=91, p=.000)$. According to these results, it can be said that the data are suitable for EFA. In EFA, first of all, 14 items were analyzed without any dimension restrictions. When the eigenvalues obtained were taken into consideration, the rotation process was performed since there were three dimensions with an eigenvalue above 1. Principal axis factoring method (PAFM) and promax rotation technique were used in the rotation process. In the literature, choosing values of .45 and higher for factor load values is a good criterion when doing EFA (Büyüköztürk, 2010). In this study, the value of .55 was preferred for factor loads. As can be seen in Table 1, nine items that were below .55 factor load value as criteria were excluded from the analysis $(4,5,6,9,10,11,12,13,14)$. The analysis was repeated as each item was removed. A one-dimensional structure that explains $47,867 \%$ of the total variance was obtained from the remaining five items. It is stated that $30 \%$ or more of the variance explained in singlefactor designs is sufficient (Büyüköztürk, 2010).

A confirmatory factor analysis (CFA) was performed on the data obtained from a different sample group in order to verify the one-dimensional structure obtained from the EFA analysis. Modification was made because sufficient fit indices could not be obtained in the first analysis results $(\chi 2 / \mathrm{df}=$ $19.963, \mathrm{CFI}=.878, \mathrm{TLI}=.756, \mathrm{GFI}=.899, \mathrm{AGFI}=.697, \mathrm{RMSEA}=.234$ and SRMR $=.0680$ ). As a modification, covariance was added between the error variances of M7-M8 items. It was determined that the values after the modification are at a good fit level as $\chi 2 / \mathrm{df}=1.684, \mathrm{CFI}=.996$, TLI=.991, GFI=.993, AGFI=.972, RMSEA=.045 ve SRMR=.0165 (Aksu, et al., 2017; Brown and Cudeck, 1993; Hooper et al., 2008; Hu and Bentler, 1999; Karagöz, 2019; Özdamar, 2016).

According to the correlation analysis between FoMOC 19S and other variables, it was found that there were a moderately positive correlation between FoMOC $19 S$ and FoMO and fear of Covid 19, respectively ( $\left.\mathrm{r}_{346}=.51 ; \mathrm{r}_{397}=.40\right)$. In addition, it was found that there was a low-level positive relationship between FoMOC 195 and internet addiction and social media addiction $\left(\mathrm{r}_{397}=\right.$ .16; r397= .15), while a low-level negative relationship ( $\mathrm{r} 397=-23)$ was found between psychological resilience and FoMOC 195. 
The Cronbach Alpha internal consistency coefficients for reliability were calculated as .79 over EFA data and .84 on the second new sample data. Mcdonald's $\omega$, another reliability test, were calculated as .82 over EFA data and .84 on the second new sample. In addition, the CR value was calculated as .83. The AVE value was found to be .51 .

According to the result obtained from the measurement invariance analysis of FoMOC 195 according to gender in the study, it was found that the configural, metric and scalar invariances of FoMOC $19 S$ were provided however, it was found that strict invariance was not provided. It was found that all invariances were provided according to marital status.

In this research, a measurement tool has been developed that measures the fear of missing out related to Covid 19, which is one of the leading topics on the agenda nowadays. As a result of the EFA for FoMOC 19S, which was prepared by taking into account the FoMO scales and related FoMO literature as well as the studies related to Covid 19, a one-dimensional structure consisting of five items was obtained (See Appendix 2).

When the results obtained from the study are evaluated in general, it can be said that the FoMOC 19S, which was prepared taking into account the coronavirus developments and agenda and the structure of fear of missing out (FoMO), is a measurement tool that gives a valid and reliable measurement with its five-item, one-dimensional structure. Being first in literature, being short, having measurement invariance for gender and marital status and studying with wide age ranges can be seen as positive aspects for FoMOC 19S. Not studied with adolescents, and the lack of measurement invariance related to measurement invariance, except for gender and marital status, can be seen as its negative aspects. In addition, concepts such as anxiety, stress, well-being and personality can be studied with FoMOC 195 in future studies.

\section{Kaynakça / References}

Abel, J.P., Buff. C.L. ve Burr, S.A. (2016). Social media and the fear of missing out: Scale development and assessment. Journal of Business \& Economics Research (JBER), 14(1), 33-44. https://doi.org/10.19030/jber.v14i1.9554. 
Ahorsu, D.K., Lin, C.Y., Imani, V., Saffari, M., Griffiths, M. D. ve Pakpour, A.H. (2020). The fear of COVID-19 scale: Development and initial validation. International Journal of Mental Health and Addiction, 1-9. https://doi.org/10.1007/s11469-020-00270-8.

Aksu, G., Eser, M. T. ve Güzeller, C. O. (2017). Açımlayıcı ve doğrulayıcı faktör analizi ile yapısal eşitlik modeli uygulamaları. Ankara: Detay Yayınclık.

Alt, D. ve Boniel-Nissim, M. (2018). Links between adolescents' deep and surface learning approaches. problematic Internet use. and fear of missing out (FoMO). Internet interventions, 13, 30-39. https://doi.org/10.1016/j.invent.2018.05.002.

Andreassen, C.S., Torsheim, T., Brunborg, G.S. ve Pallesen S. (2012). Development of a Facebook addiction scale. Psychological Reports, 110: 501-517 https://doi.org/10.2466/02.09.18.PR0.110.2.501-517.

Başusta, N.B. ve Gelbal, S. (2015). Gruplararası karşılaştırmalarda ölçme değişmezliğinin test edilmesi: PISA öğrenci anketi örneği. Hacettepe Üniversitesi Ĕ̆itim Fakültesi Dergisi, 30(4), 80-90.

Blackwell, D., Leaman, C., Tramposch, R., Osborne. C. ve Liss, M. (2017). Extraversion. neuroticism. attachment style and fear of missing out as predictors of social media use and addiction. Personality and Individual Differences, 116, 69-72. https://doi.org/10.1016/j.paid.2017.04.039.

Browne, M. W. ve Cudeck, R. (1993). Alternative ways of assessing model fit. K. A.Bollen ve J. S. Long (Eds.), Testing structural equation models içinde (s. 136-162). Newbury Park, CA: Sage.

Büyüköztürk, Ş. (2010). Sosyal bilimler için veri analizi el kitabı (11.Baskı) / Data analysis handbook for social sciences. Ankara: Pegem Akademi.

Can, G. ve Satici, S. A. (2019). Adaptation of fear of missing out scale (FoMOs): Turkish version validity and reliability study. Psicologia: Reflexão $e$ Crítica, 32, 3, 1-7, https://doi.org/10.1186/s41155-019-0117-4.

Chen, F. (2007). Sensitivity of goodness of fit indexes to lack of measurement invariance. Structural Equation Modelling, 14(3), 464-504. https://doi.org/doi: 10.1080/10705510701301834.

Cheung, G. W. ve Rensvold. R. B. (2002). Evaluating goodness-of-fit indexes for testing measurement invariance. Structural equation modeling, 9(2), 233255. https://doi.org/10.1207/S15328007SEM0902 5.

Curran, P.J., West, S.G. ve Finch, J.F. (1996). The robustness of test statistics to nonnormality and specification error in confirmatory factor analysis. Psychological methods, 1(1), 16-29. 
Çerçi, Ü. Ö., Canöz, N., ve Canöz, K. (2020). Covid-19 Krizi Döneminde Bilgilenme Aracı Olarak Sosyal Medya Kullanımı. Selçuk Üniversitesi Sosyal Bilimler Enstitüsü Dergisi, 44, 184-198.

Çınar, Ç.Y. ve Mutlu. E. (2018). Predictors for fear of missing out in the social networks among university students. Current Addiction Research, 2(2), 47-53. https://doi.org/10.5455/car.105-1540197312.

Demirci, İ. (2019). Bergen sosyal medya bağımlılığı ölçeğinin Türkçeye uyarlanmasi, depresyon ve anksiyete belirtileriyle ilişkisinin değerlendirilmesi. Anatolian Journal of Psychiatry/Anadolu Psikiyatri Dergisi, 20 (Ek sayı.1):15-22. https://doi.org/10.5455/apd.41585.

Dempsey, A.E., O'Brien, K.D., Tiamiyu, M.F. ve Elhai, J. D. (2019). Fear of missing out (FoMO) and rumination mediate relations between social anxiety and problematic Facebook use. Addictive Behaviors Reports, 9, 100150. https://doi.org/10.1016/j.abrep.2018.100150.

Doğan, T. (2015). Kısa psikolojik sağlamlık ölçeği'nin Türkçe uyarlaması: Geçerlik ve güvenirlik çalışması. The Journal of Happiness \& Well-Being, 3(1), 93102.

Elhai, J.D., Gallinari, E.F., Rozgonjuk, D. ve Yang, H. (2020). Depression, anxiety and fear of missing out as correlates of social, non-social and problematic smartphone use. Addictive Behaviors, 105. 106335. https://doi.org/10.1016/j.addbeh.2020.106335.

Ercengiz, M. (2020). Mediator effect of FOMO in the relationship between impulsivity and social media craving. OPUS International Journal of Society Researches, 15(22), 854-877. https://doi.org/10.26466/opus.648795.

George, D., ve Mallery, M. (2010). SPSS for Windows Step by Step: A Simple Guide and Reference, 17.0 update (10a ed.) Boston: Pearson.

Gezgin, D.M., Hamutoglu, N.B., Sezen-Gultekin, G. ve Gemikonakli, O. (2018). Relationship between nomophobia and fear of missing out among Turkish university students. Cypriot Journal of Educational Science, 13(4),549561. https://doi.org/10.18844/cjes.v13i4.3464.

Gürbüz, S. (2019). AMOS ile yapısal eşitlik modellemesi, temel ilkeler ve uygulamah analizler. Ankara: Seçkin Yayıncilı.

Hair, J.F., Black, W.C., Babin, B. J., ve Anderson, R. E. (2014). Multivariate data analysis. (7th Ed.). Harlow, UK: Pearson Education Limited. 
Hishan, S.S., Ramakrishnan, S. ve Qureshi, M. I. (2020). Smartphone addiction, fear of missing out, and perceived competence as predictors of social media addiction of adolescents. Journal of Critical Reviews, 7(16), 1172-1181. https://doi.org/10.31838/jcr.07.16.148.

Holte, A. J. ve Ferraro, F.R. (2020). Anxious, bored, and (maybe) missing out: Evaluation of anxiety attachment, boredom proneness, and fear of missing out (FoMO). Computers in Human Behavior, 112, 106465. https://doi.org/10.1016/j.chb.2020.106465.

Hooper, D., Coughlan, J. ve Mullen, M. (2008). Structural equation modelling: Guidelines for determining model fit. Electronic Journal of Business Research Methods, 6(1):53-60. https://doi.org/10.21427/D7CF7R.

Hoşgör, H. ve Hoşgör, D.G. (2019). The relationship among nomophobia. fear of missing out and demographic variables: Example of the healthcare manager candidates. Current Addiction Research 3(1), 16-24. https://doi.org/10.5455/car.105-1562758780.

Hu, L.T. ve Bentler, P.M. (1999). Cutoff criteria for fit indexes in covariance structure analysis: Conventional criteria versus new alternatives. Structural Equation Modeling: A Multidisciplinary Journal, 6(1), 1-55. https://doi.org/10.1080/10705519909540118.

Kalayci, S. (2005). SPSS uygulamali çok degiskenli istatistik teknikleri. Ankara: Asil Yayin Dagitim.

Karaaslan-Eşer, A. ve Alkaya, S.A.(2019). Examination of nursing students' social media addiction and fear of evading developments. University of Health Sciences Journal of Nursing, 1(1), 27-36.

Karagöz, Y. (2019). SPSS-AMOS-META uygulamalı nitel, nicel, karma bilimsel araştırma yöntemleri ve yayın etiği (2.basım). Ankara: Nobel Akademik Yayıncilik.

Kartol, A. ve Peker, A. (2020). The Investigation of predictors of fear of missing out (FOMO) in adolescents. OPUS International Journal of Society Researches, 15(21), 454-474. https://doi.org/10.26466/opus.628081.

Koçer. M. (2012). Internet and social media habits of Erciyes university students. Akdeniz Communication,18, 70-85.

Kutlu, M., Savcl, M., Demir, Y. ve Aysan, F. (2016). Young internet bağımlılı̆̆ı testi kısa formunun Türkçe uyarlaması: Üniversite öğrencileri ve ergenlerde geçerlilik ve güvenilirlik çalışması. Anadolu Psikiyatri Dergisi, 17(Ek.1), 69-76. https://doi.org/10.5455/apd.190501. 
Küçükttğll, M.S. (2020). Korona virüsü günlerinde internet ve sosyal medya kullanım. The Journal of Academic Social Science Studies, 13(81), 573-593. https://dx.doi.org/10.29228//ASSS.45881.

Li, L., Griffiths, M.D., Mei, S. ve Niu. Z. (2020). Fear of missing out and smartphone addiction mediates the relationship between positive and negative affect and sleep quality among chinese university students. Frontiers in Psychiatry, 11, 877, 110. https://doi.org/10.3389/fpsyt.2020.00877.

Meng, R., Li, J., Wang, Z., Zhang, D., Liu, B., Luo, Y., ... ,Yu, C. (2020). The chinese version of the perceived stress questionnaire: Development and validation amongst medical students and workers. Health and quality of life outcomes, 18(1), 1-17. https://doi.org/10.1186/s12955-020-01307-1.

Metin, B., Pehlivan, R. ve Tarhan, N. (2017). Realiability and validity of Uskudar fear of missing out scale. The Journal of Neurobehavioral Sciences, 4,2, 4346. https://doi.org/10.5455/JNBS. 1494334674.

Özdamar, K. (2016). Ölçek ve test geliştirme yapısal eşitlik modellemesi. Eskişehir: Nisan Kitabevi.

Pawlikowski, M, Altstötter-Gleich, C. ve Brand, M. (2013). Validation and psychometric properties of a short version of Young's internet addiction test. Computers in Human Behaviour, 29(3): 1212- 1223 . https://doi.org/10.1016/j.chb.2012.10.014.

Przybylski, A.K., Murayama, K., DeHaan, C.R. ve Gladwell, V. (2013). Motivational, emotional, and behavioral correlates of fear of missing out. Computers in Human Behavior, 29(4), 1841-1848. https://doi.org/10.1016/j.chb.2013.02.014.

Rehman, S., Goyal, S., Tandon, S., Hira, N. ve Ahuja, K. (2019) Ocean of fomocorrelation between fear of missing out (FOMO). Personality and social media engagement. Phonix International Journal For Psychology and Social Sciences, 3(2), 41-58.

Riordan, B.C., Cody, L., Flett, J.A.M., Tamlin, S.C., Hunter, J ve Scarf, D. (2020) The development of a single item FoMO (Fear of Missing Out) scale. Current Psychology 39, 1215-1220.https://doi.org/10.1007/s12144018-9824-8.

Satici, B., Gocet-Tekin, E., Deniz, M.E. ve Satici, S. A. (2020). Adaptation of the Fear of COVID-19 Scale: Its association with psychological distress and life satisfaction in Turkey. International Journal of Mental Health and Addiction, 1-9. https://doi.org/10.1007/s11469-020-00294-0. 
Sette, C. P., Lima, N.R., Queluz, F.N., Ferrari, B.L. ve Hauck. N. (2020). The online fear of missing out inventory (ON-FoMO): Development and validation of a new tool. Journal of Technology in Behavioral Science, 5(1), 20-29. https://doi.org/10.1007/s41347-019-00110-0.

Solmaz. B.. Tekin. G.. Herzem. Z.. \& Demir. M. (2013). An application on the use of internet and social media. Selçuk Communication. 7. 4. 23-32.

Smith, B.W., Dalen, J., Wiggins, K., Tooley, E., Christopher, P. ve Bernard, J. (2008). The brief resilience scale: Assessing the ability to bounce back. International Journal of Behavioral Medicine, 15, 194-200. https://doi.org/10.1080/10705500802222972.

Şener. G. (2020). The Views of vocational higher education students on social media use. Journal of Kirsehir Education Faculty,21(1), 183-216. https://doi.org/10.29299/kefad.2020.21.01.006.

Tang, G., Hung, E. P., Au-Yeung, H.K.C. ve Yuen. S. (2020). Politically motivated internet addiction: Relationships among online information exposure, internet addiction, FOMO, psychological well-being, and radicalism in massive political turbulence. International Journal of Environmental Research and Public Health, 17(2), 633, 1-13. https://doi.org/10.3390/ijerph17020633.

Traş, Z. ve Öztemel, K. (2019). Examining the relationships between facebook intensity, fear of missing out, and smartphone addicition. Addicta: The Turkish Journal on Addictions 6, 91-113. http://dx.doi.org/10.15805/addicta.2019.6.1.0063

Wegmann, E., Oberst, U., Stodt, B. ve Brand, M. (2017). Online-specific fear of missing out and Internet-use expectancies contribute to symptoms of Internet-communication disorder. Addictive Behaviors Reports, 5, 33-42. https://doi.org/10.1016/j.abrep.2017.04.001.

Wolniewicz, C.A., Rozgonjuk, D. ve Elhai J.D. (2020). Boredom proneness and fear of missing out mediate relations between depression and anxiety with problematic smartphone use. Human Behavior and Emerging Technologies.,2:61-70. https://doi.org/10.1002/hbe2.159.

World Health Organization (WHO)(2021). WHO Coronavirus Disease (COVID19) Dashboard, 8 Şubat 2021'de https://covid19.who.int/ adresinden erişildi.

Young KS. (1998). Caught in the Net: How to recognize the signs of internet addiction and a winning strategy for recovery. New York: John Wiley \& Sons. 


\section{Ekler}

EK 1. K19-GKK Ölçeği Maddeleri

\begin{tabular}{|c|c|c|c|c|c|c|}
\hline No & $\begin{array}{l}\text { 1=Hiç Uygun Değil, 2=Çok Az Uygun, 3=Biraz Uygun, } \\
\text { 4=Uygun, 5=Tamamen Uygun }\end{array}$ & & & & & \\
\hline 1 & $\begin{array}{l}\text { Sosyal medyada Kovid 19'la ilgili son dakika haberlerini kaçırmaktan } \\
\text { korkarım. }\end{array}$ & 1 & 2 & 3 & 4 & 5 \\
\hline 2 & $\begin{array}{l}\text { Sosyal medyada Kovid 19'la ilgili bir bilgiyi ve/veya haberi kaçırmak- } \\
\text { tan dolayı korku duyarım. }\end{array}$ & 1 & 2 & 3 & 4 & 5 \\
\hline 3 & $\begin{array}{l}\text { Sosyal medyada Kovid'19'la ilgili dünyadaki gelişmeleri kaçırmak beni } \\
\text { endişelendirir. }\end{array}$ & 1 & 2 & 3 & 4 & 5 \\
\hline 4 & $\begin{array}{l}\text { Sosyal medyada Kovid 19'la ilgili gündemden uzak kalma düşüncesi } \\
\text { bile beni gerer. }\end{array}$ & 1 & 2 & 3 & 4 & 5 \\
\hline 5 & $\begin{array}{l}\text { Yakınlarımın başına Kovid 19'la ilgili bir şey geldi mi diye (örn, ölüm, } \\
\text { hastalığa yakalanma vb) sık sık sosyal medya hesaplarımı kontrol } \\
\text { ederim. }\end{array}$ & 1 & 2 & 3 & 4 & 5 \\
\hline
\end{tabular}

\section{Appendix 2. FoMOC 19S Items}

\begin{tabular}{|c|c|c|c|c|c|c|}
\hline No & $\begin{array}{l}1=\text { Not at all appropriate", } 2={ }^{\prime \prime} \text { Rarely appropriate", } 3=" \text { Somewhat appr } \\
\text { priate", or } 5=\text { "Completely appropriate }\end{array}$ & & & & & \\
\hline 1 & $\begin{array}{l}\text { I'm afraid of missing the breaking news about Covid } 19 \text { on social me- } \\
\text { dia. }\end{array}$ & 1 & 2 & 3 & 4 & 5 \\
\hline 2 & $\begin{array}{l}\text { I am afraid of missing information and / or news about Covid } 19 \text { on } \\
\text { social media. }\end{array}$ & 1 & 2 & 3 & 4 & 5 \\
\hline 3 & $\begin{array}{l}\text { It worries me to miss developments in the world about Covid } 19 \text { on } \\
\text { social media. }\end{array}$ & 1 & 2 & 3 & 4 & 5 \\
\hline 4 & $\begin{array}{l}\text { Even the thought to keep away from the agenda concerning Covid } 19 \\
\text { on social media makes me uneasy. }\end{array}$ & 1 & 2 & 3 & 4 & 5 \\
\hline 5 & $\begin{array}{l}\text { I frequently check my social media accounts whether anything con- } \\
\text { cerning COVID-19 happens to my relatives (e.g., death and infection). }\end{array}$ & 1 & 2 & 3 & 4 & 5 \\
\hline
\end{tabular}

*For this instrument, validity and reliability analyses have only been carried out in Turkish Languge, not in other languages.

\section{Kaynakça Bilgisi / Citation Information}

Pamuk, M. (2021). Kovid 19 ile ilgili gelişmeleri kaçırma korkusu ölçeğinin geliştirilmesi: Geçerlik ve güvenirlik çalışması. OPUS-Uluslararası Toplum Araştırmaları Dergisi, 17(Pandemi Özel Sayısı), 3309-3335xx. DOI: $10.26466 /$ opus. 876588 